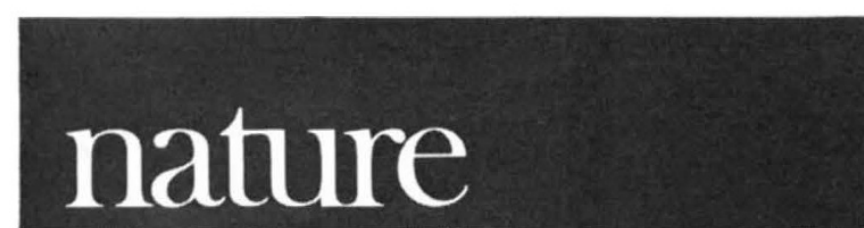

Volume 251

October 4, 1974 revolution is now well advanced. Admittedly the Soviet Union seems to lag two or three years, but for both sides it is becoming plain that accuracy and sophistication is replacing numerical growth in the strategic game. Unfortunately since neither side is able, in its monitoring, to do much more than count devices, the prospects for verified arms limitations (and verifications is probably a sine qua non) diminish with time.

A case could be made that these qualitative improvements should be allowed to run their course. After all, if it will be possible to deliver nuclear warheads with an accuracy of a metre by 1990 , as some believe, the payload could be reduced and the tradition that the military fights the military and does not draw in the general public might be re-established. There must always be the hope that war could be restricted to surgical strikes.

There are several reasons, however, why we cannot expect to have neat wars fought for us entirely by technology. An obvious one is that there are bound to be more than two participants in any future major war, and since the superpowers, in their pursuit of technological sophistication, have actively, if inadvertently, encouraged other countries to go nuclear but at a less sophisticated level, the multiplicity of nuclear-armed participants will inevitably confuse any bilateral game plan. But there is a more subtle reason why we should not believe that wars of opposing and highly sophisticated technologies will be more bearable for the civilian.

No nation would be satisfied that its future be decided entirely by surrogates. It is unlikely that the idea of a football match, say, between the superpowers-once the shape of the ball had been decided-would be deemed an acceptable way of settling political disputes. There has to be some personal involvement and sacrifice in war, and the growing trend away from this that we see in present and future strategic hardware poses an interesting question. If the early nuclear age has been marked by an uneasy truce between the superpowers because the consequences of major war were unspeakable, maybe the coming nuclear age will see further detente because a technologist's war between machines having reduced the unspeakable is politically unacceptable.

\section{A hundred years ago} independently targeted; there is nothing in SALT to stop the upgrading of all of these to MIRV capability.

The Soviet Union is constrained to 1,618 silos and is now within 43 of that number. She can have 313 'heavy' missiles (with yields up to 25 megatons) and is close to that total. The remainder are at present mostly megaton SS-9 missiles, but MIRVing is on the way for these too. - At sea, the United States is permitted 41 nuclear submarines with 710 missiles. At present half of the fleet is MIR Ved (each missile containing at least ten 50-kiloton vehicles) but not all the rest will go this way, as ten Polaris boats will be pulled out of action in the late seventies and beyond, to be replaced by 24-tube Tridents. The warheads in Trident are MARVs - manoeuvrable re-entry vehicles, capable of manoeuvre after re-entry to avoid defences.

- The Soviet Navy is restricted to 62 'modern' submarines and is still 20 short of that figure, but building fast. As yet the 660 warheads carried are not multiple vehicles, but tests are under way.

The message is thus from all fronts that the qualitative

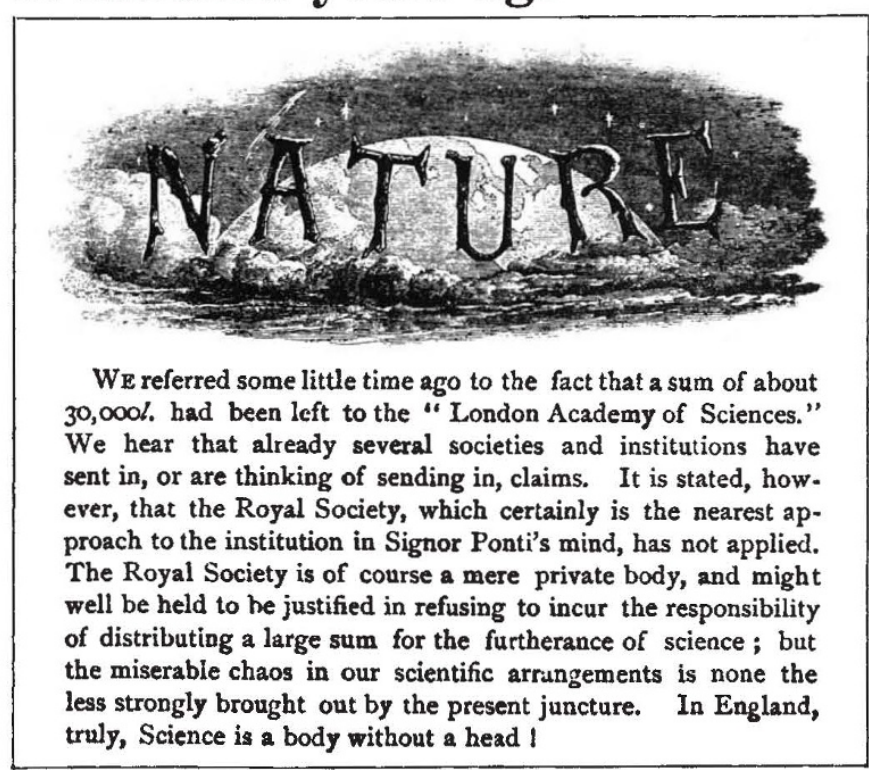

From Nature, 10, 470, October 8, 1874. 